\title{
Awareness about Risk Factors in Patients after an Acute Heart Attack, An Exploratory Study in Albania
}

\author{
Msc. Valbona Alliu ${ }^{1}$, Phd. Alketa Hoxha $(\text { Qosja })^{2}$, Prof. Dr. Petrit Bare ${ }^{3}$ \\ ${ }^{1,2}$ University of Medicine, Faculty of Technical Medical Sciences, Tirana, Albania \\ ${ }^{3}$ Cardiologist, Dean of Faculty of Technical Medical Sciences, University of Medicine, Tirana, Albania
}

\begin{abstract}
Background: Cardiac educational programs are intended to prevent the recurrence of heart failure and improve patients' quality of life. Public awareness of risk factors for ischemic heart disease is essential, but no measures of it exist in Albania where it is on the rise and the incidence of MI and other cardiac diseases are dramatically increasing. Aim: The aim of our study is to assess the knowledge levels of the risk factors in patients after an acute heart attack, because this information is the cornerstone for developing an educational program based on patients' needs. Methods: This is a descriptive study. We recruited 100 patients after an acute heart attack aged between 32-34 years old. Self-report questionnaires, which included general characteristics, disease-related characteristics and a pre-test/post-test design was conducted to assess needs of the patients, changes in knowledge and self-care abilities. Results: We found that more than $90 \%$ of patients desired information, particularly about heart failure symptoms, time to notify healthcare providers, prognosis, and exercise/physical activity. Of the 100 participants $61 \%$ were male, 59\% were aged between 55 and 74 years, and $31.6 \%$ had not completed ten years education. Conclusions: Albanian patients after an acute cardiac event had a low level of knowledge about these diseases. These conditions can negatively affect clinical outcomes. This pilot study has indicated that a patient-centre educating is beneficial and is associated with an improvement in patients' knowledge and self-care abilities. Relevance to clinical practice: Therefore, this study will provide a basis for encouraging Albanian patients to obtain information about their disease and to guide professionals in developing education programs.
\end{abstract}

Keywords: patients after an acute heart attack, self-educational, healthcare professionals, self-care abilities.

\section{Introduction}

CVDs are the leading cause of deaths in both developed and developing countries. In 2008, 30\% (17.5 million people) of global all-cause mortalities were from CVDs. Of these, 6.2 and 7.3 million were due to stroke and CHD, respectively. It is expected to increase to 23.3 million by $2030^{[1,2]}$. Cardiac diseases are no longer restricted by geographical area or by age, sex, or socioeconomic boundaries. Heart disease has already reached epidemic magnitudes in poorer countries. Cardiovascular disease (CVD) is one of the most preventable causes of death in the world, due to the fact that the majority of its risk factors are preventable or controllable, such as hypertension, dyslipidemia, diabetes, obesity, smoking, lack of physical activity, stress, unhealthy dietary practices and diabetes ${ }^{[3]}$.

Patient education is key in order to detecting changes in body weight or clinical status early enough to allow the patient or a healthcare provider an opportunity to institute treatments that can prevent clinical deterioration in those patient with heart failure ${ }^{[4-5]}$. The level of awareness of cardiovascular health modifiers among the Albanian population has not been clearly quantified. However, education of patients and their caregiver(s) can often be complex. It is critical for patients and their caregiver(s) to understand how best to comply with physicians and other healthcare providers instructions. Understanding care instructions has been associated with improved patient outcomes, such as reduced hospital readmissions. Knowledge of the risk factors is an important step in the modification of lifestyle behaviors conducive to optimal cardiovascular health in developing countries. Yet, little is known about the CVD knowledge in the Eastern Mediterranean region, where only two studies were published. The first was conducted in the Gulf Cooperation Council (GCC) countries to assess the level of awareness of stroke risk factors and symptoms among the general population ${ }^{[6]}$. The second was conducted in Jordan to examine the public knowledge and awareness of CVD and its risk factors ${ }^{[7]}$.

The goals of heart failure patient education are to help patients and their caregiver(s) acquire the knowledge, skills, strategies, problem solving abilities, and motivation necessary for adherence to the treatment plan and effective participation in self-care. Upon discharge, patient and caregiver(s) should be aware and supportive of self-care follow-up plans, how to care out self-care follow-up plans, and understand the importance of adherence to a patient's health-related quality of life ${ }^{[8]}$. A lot of changes were in our country during transition period and the major transitions have had apparent influences on behavioural, social, and lifestyle patterns. Several studies showed insufficient knowledge and poor compliance to non-pharmacological management in heart failure patients.

\section{Aim}

The aim of our study is to assess the knowledge levels of the risk factors in patients after an acute heart attack, because this information is the cornerstone for developing an educational program based on patients' needs. 


\section{International Journal of Science and Research (IJSR) \\ ISSN (Online): 2319-7064}

Index Copernicus Value (2013): 6.14 | Impact Factor (2014): 5.611

\section{Methods}

A descriptive study was performed in Polyclinic Nr.10 in Tirana, state polyclinic. This survey was conducted during the period from January to December 2015.

Ethical approval for this study was obtained from the Faculty of Technical Medical Sciences, University of Medicine, Tirana, Albania

Patients, who had passed an acute heart attack, were contacted and given an explanation with regard to the purpose of the study. They were free to refuse participation in the study. Data were collected anonymously via selfadministered questionnaire. Those who agreed to take part in the study were given the questionnaires which were completed anonymously.

We recruited 100 patients after a cardiac event with age between 33-78 years old.

The enrolled patients were interviewed with structured questionnaire enquiring into their awareness of risk factors for a cardiac event and their knowledge level regarding these disease. To assess knowledge and identify risk factors, an indepth structured interview questionnaire was prepared after review of literature. The first part of this questionnaire collect information about age, gender, weight, education, occupation.

The structured interview questionnaire with 20 questions with Yes/No choices or multiple choice questions related to modifiable risk factors of a cardiac event and to assess the knowledge about general awareness, clinical manifestations and prevention of ischemic heart disease and preventable or controllable risk factors such as hypertension, dyslipidemia, diabetes, obesity, smoking, lack of physical activity, stress, unhealthy dietary practices and diabetes.

\section{Results}

The 100 patients consisted of 61(61\%) male (aged $46.45 \pm 11.12$ years) and 39(39\%) females (aged $45 \pm 10.77$ years) [Table 1], [Figure 1].

The $32(32 \%)$ patients were primary education, $40(40 \%)$ intermediate and $28(28 \%)$ were graduates [Table 2], [Figure 2]. It was found that mean weight of 61 male patients $(67.76 \pm 17.62)$ was higher than mean weight of 39 female patients $(59.7 \pm 13.79)$.

We found that more than $90 \%$ of patients desired information, particularly about heart failure symptoms, time to notify healthcare providers, prognosis, and exercise/physical activity.

$15(15 \%)$ were between the age group $30-40$ years, 26 $(26 \%)$ were between 40 - 50 years,

$29(29 \%)$ were between 50-60 years and $30(30 \%)$ were above 60 years of age [Table 3], [Figure 3].

Table 1: Frequency and percentage distribution of gender characteristics of patients after an acute cardiac event

\begin{tabular}{|c|c|c|c|}
\hline & $\begin{array}{c}\text { Male } \\
(\mathrm{n}, \%)\end{array}$ & $\begin{array}{c}\text { Female } \\
(\mathrm{n}, \%)\end{array}$ & $\begin{array}{c}\text { Total } \\
(\mathrm{n}, \%)\end{array}$ \\
\hline Number of participants & 61 & 39 & 100 \\
& $61 \%$ & $39 \%$ & $100 \%$ \\
\hline
\end{tabular}

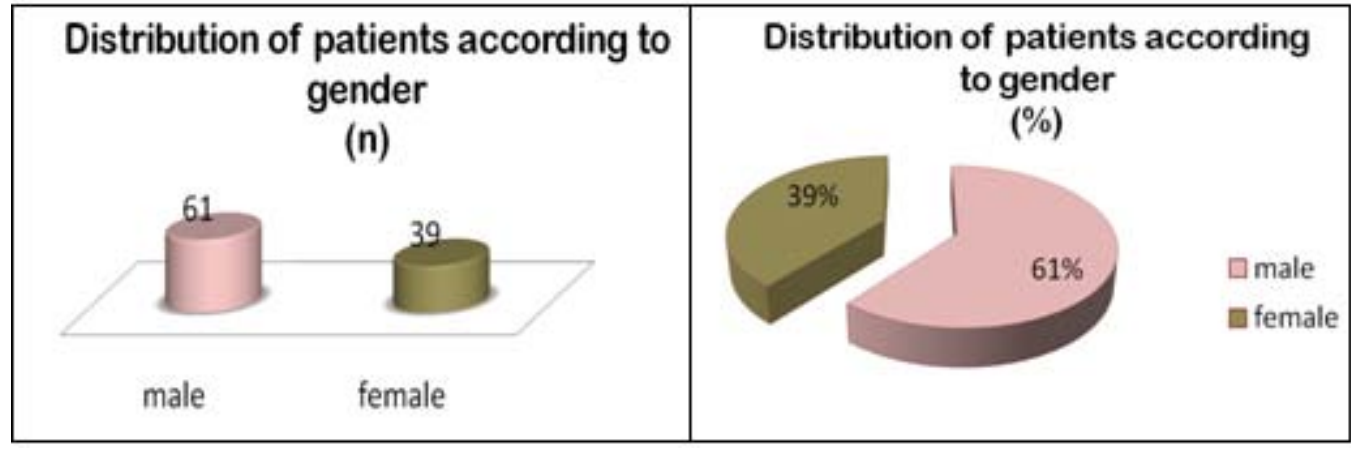

Figure 1: Frequency and percentage distribution of gender characteristics of patients after an acute cardiac event

Table 2: Frequency and percentage distribution of patients related education after an acute cardiac event

\begin{tabular}{|c|c|}
\hline Distribution of patients related education & Frequency $(n, \%)$ \\
\hline$<10$ years & $3232 \%$ \\
\hline High school & $4040 \%$ \\
\hline University & $2828 \%$ \\
\hline Total & $100100 \%$ \\
\hline
\end{tabular}




\section{International Journal of Science and Research (IJSR) \\ ISSN (Online): 2319-7064}

Index Copernicus Value (2013): 6.14 | Impact Factor (2014): 5.611

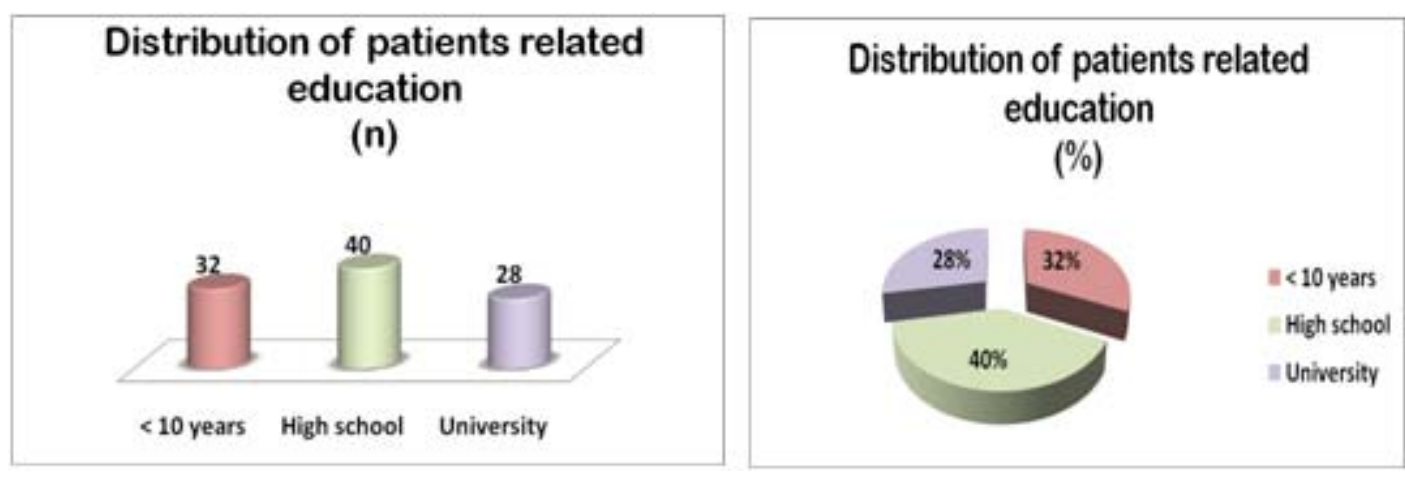

Figure 2: Frequency and percentage distribution of patients related education after an acute cardiac event

Table 3: Frequency and percentage distribution of patients related to age after an acute cardiac event

\begin{tabular}{|c|c|}
\hline Distribution of patients related to age & Frequency $(n, \%)$ \\
\hline $30-40$ years & $1515 \%$ \\
\hline $40-50$ years & $2626 \%$ \\
\hline $50-60$ years & $2929 \%$ \\
\hline$>60$ years & $3030 \%$ \\
\hline Total & $100100 \%$ \\
\hline
\end{tabular}

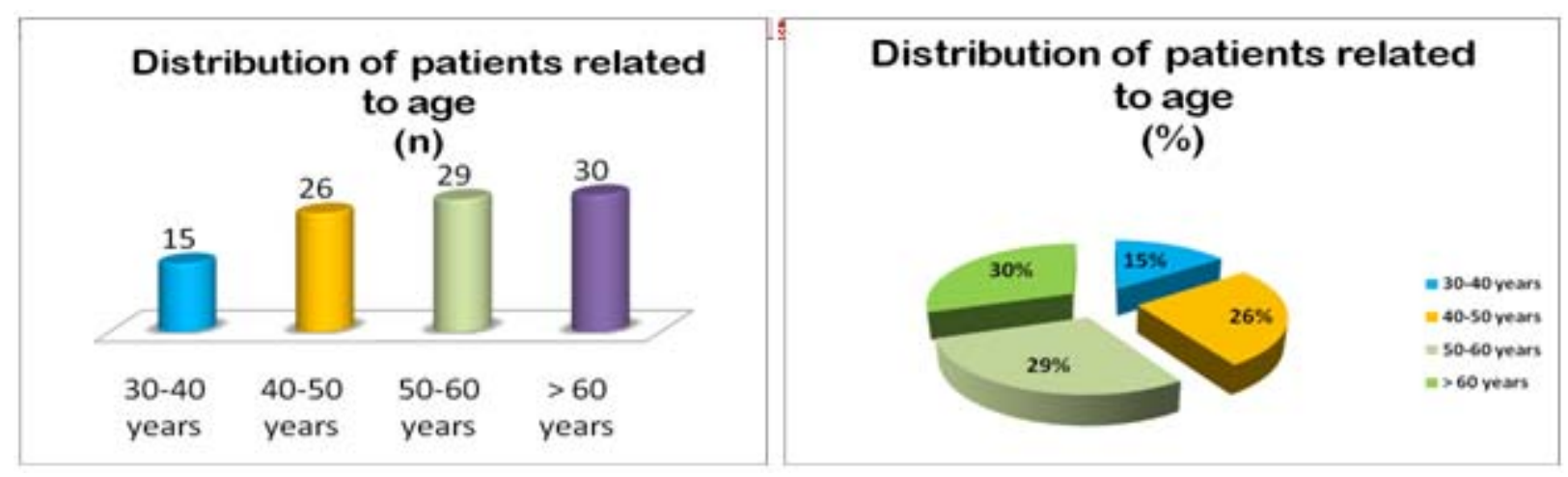

Figure 3: Frequency and percentage distribution of patients related to age after an acute cardiac event

Table 4: Frequency and percentage distribution of awareness of risk factors by the respondents

\begin{tabular}{|c|c|}
\hline Awareness of risk factors by the respondents & Frequency (n, \%) \\
\hline A-smoking & $6565 \%$ \\
\hline B-hypertension & $6161 \%$ \\
\hline C-regular health checkup & $2121 \%$ \\
\hline D- stress in family & $4040 \%$ \\
\hline E- no exercise & $2929 \%$ \\
\hline
\end{tabular}

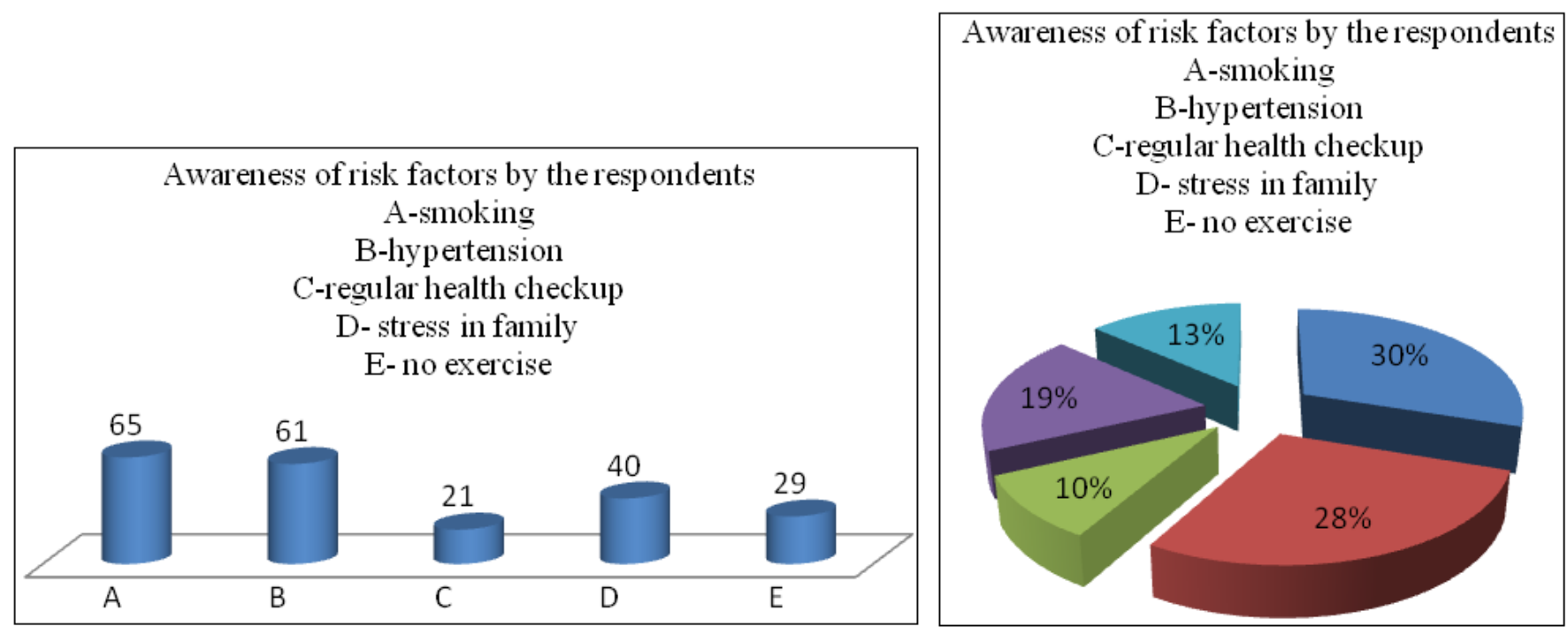

Figure 4: Frequency and percentage distribution of awareness of risk factors by the respondents 


\section{International Journal of Science and Research (IJSR) \\ ISSN (Online): 2319-7064}

Index Copernicus Value (2013): 6.14 | Impact Factor (2014): 5.611

Table 5, Figure 5: Frequency and percentage distribution of risk factors of patients involved in the study

\begin{tabular}{|l|l|}
\hline \multicolumn{1}{|c|}{ Risk factors } & Frequency $(n, \%)$ \\
\hline Smoking & $6464 \%$ \\
\hline Alcoholism & $5151 \%$ \\
\hline Diagnosed with hypertension & $4242 \%$ \\
\hline Diagnosed with diabetic mellitus & $3939 \%$ \\
\hline Family history of cardiac disease & $1919 \%$ \\
\hline Absence of regular exercises & $7676 \%$ \\
\hline Feel depressed most of the time & $5959 \%$ \\
\hline Live in urban community & $100100 \%$ \\
\hline Problems with sexual life & $4545 \%$ \\
\hline Attending regular medication check ups & $2121 \%$ \\
\hline
\end{tabular}

\section{Discussion}

Economic growth in Albania has brought about marked change in lifestyle and in patterns of health and disease. The lifestyle If Albanians has become more sedentary and consumption of healthy food such as vegetarian food has decreased while the consumption of animal fats has increased. Rigarding health status, morbidity and mortality from coronary Heart Disease (CHD) rapidly increase. Various lifestyle factors such as, smoking, lack of exercise and inappropriate diet are the risk factors of atherosclerosis. Physiological factors such as, obesity, high Serum lipid level (cholesterol, triglyceride, HDL cholesterol and LDL cholesterols) and high blood pressure are also known as risks factors ${ }^{[9]}$.

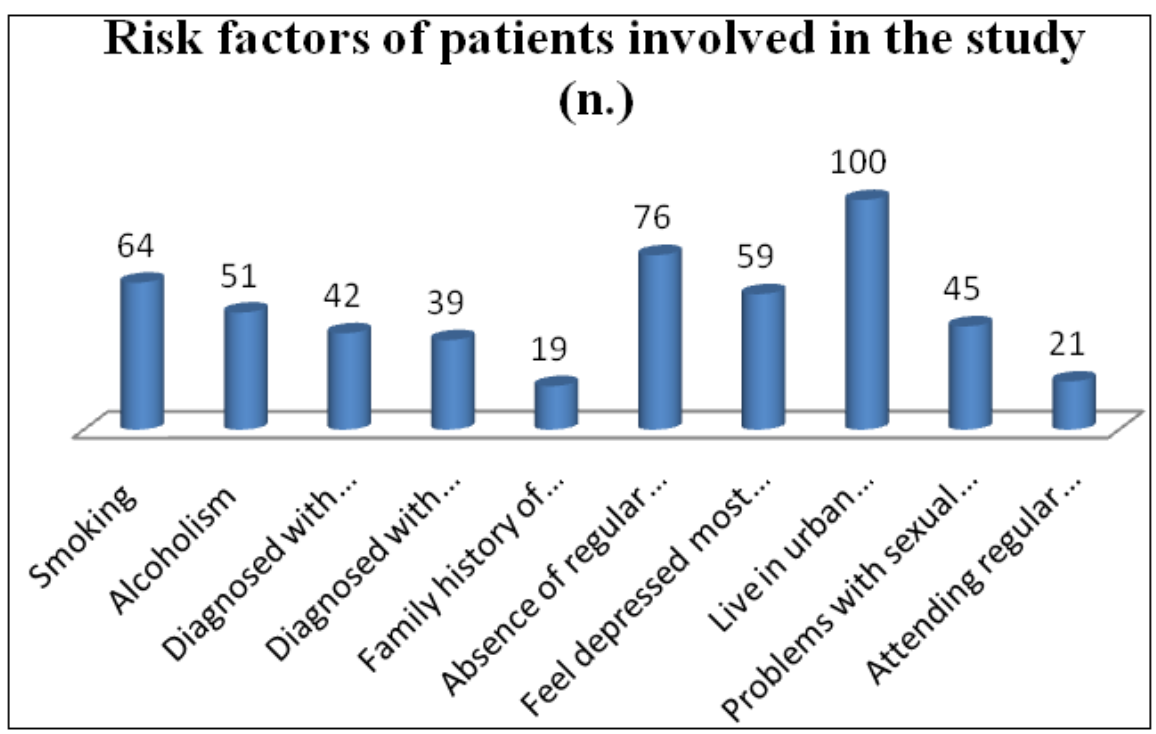

Regarding gender of patients $61 \%$ (61) were males and 39\% (39) were females. The findings related to gender were similar in other study ${ }^{[10,11]}$.

Regarding mean weight of the patients we found that mean male weight were $67.76 \pm 17.62$ and mean female weight were $59.7 \pm 13.79$. The findings related to mean weight were similar in other studies ${ }^{[12,13]}$.

Regarding education 32\% (32) had primary education, $40 \%$ (40 intermediate and 28\% (28) were graduates. The findings related to education were similar in other study ${ }^{[11]}$.

$15(15 \%)$ were between the age group $30-40$ years, 26 $(26 \%)$ were between $40-50$ years,

$29(29 \%)$ were between 50-60 years and $30(30 \%)$ were above 60 years of age ${ }^{[10,12,13]}$.

In present study, 64\% (64) had the habit of smoking and $51 \%$ (51) had the habit of alcoholism, results were almost similar with other studies ${ }^{[10,11,12,13]}$.
Mostly, 65\% (65) had average level of knowledge regarding of awareness of risk factor as smoking, hypertension and stress in family but not for regular health checkup and daily exercises, $21 \%$ (21) of patients ${ }^{[13,14,15]}$.

We found that more than $90 \%$ of patients desired information, particularly about heart failure symptoms, time to notify healthcare providers, prognosis, and exercise/physical activity.

\section{Conclusions}

Albanian patients after an acute cardiac event had a low level of knowledge about these diseases. These conditions can negatively affect clinical outcomes. This pilot study has indicated that a patient-centre educating is beneficial and is associated with an improvement in patients' knowledge and self-care abilities. 


\section{Relevance to Clinical Practice}

Therefore, this study will provide a basis for encouraging Albanian patients to obtain information about their disease and to guide professionals in developing education programs. This is the first questionnaire that has been developed to assess patients' beliefs about cardiac rehabilitation in our country. The evaluation is encouraging, showing evidence of internal reliability and validity, BUT, our study has limitations and further studies are necessary to fully validate the questionnaire.

\section{References}

[1] Krumholz HM, Amatruda J, Smith GL, Mattera JA, Roumanis SA, Radford MJ, et al. Randomized trial of an education and support intervention to prevent readmission of patients with heart failure. J Am Coll Cardiol 2002; 39:83-9.

[2] World Health Organization: Cardiovascular diseases (CVDs): Fact sheet No. 317.

[3] Abdelmoneim Awad and Hala Al-Nafis. Public knowledge of cardiovascular disease and its risk factors in Kuwait: a cross-sectional survey. BMC Public Health 2014, 14:1131

[4] ACC/AHA 2009 Guideline Update for the Diagnosis and Management of Chronic Heart Failure in the Adult. CIRCULATIONAHA.109.192064.

[5] HFSA 2010 Comprehensive Heart Failure Practice Guideline: Section 8: Disease Management, Advance Directives, and End-of-Life Care in Heart Failure Education and Counseling.

[6] Kamran S, Bener AB, Deleu D, Khoja W, Jumma M, Al Shubali A, Inshashi J, Sharouqi I, Al Khabouri J: The level of awareness of stroke risk factors and symptoms in the Gulf Cooperation Council countries: Gulf Cooperation Council stroke awareness study. Neuroepidemiology 2007, 29:235-242.

[7] Mukattash TL, Shara M, Jarab AS, Al-Azzam SI, Almaaytah A, Al Hamarneh YN: Public knowledge and awareness of cardiovascular disease and its risk factors: a cross-sectional study of 1000 Jordanians. Int J Pharm Pract 2012, 20:367-376.

[8] Kerzman H, Baron-Epel O, Toren O. What do discharge patients know about their medication? Patient Educ Couns 2005; 56(3):276-82.

[9] Han Ym, oh MH, Km S. Clinical study on the factors of atherosclerosis in adult male. Family physician 1989; 10:29-35.

[10]Dowse GK, Gareeboo H, Alberti KG, Zimmet P, Tuomilehto J, et al. Changes in population cholesterol concentrations and other cardiovascular risk factor levels after five years of the non-communicable disease intervention programme in Mauritius. Mauritius Noncommunicable Disease Study Group. BMJ. 1995 Nov 11;311(7015):1255-9.

[11] Khalid Y, Malina O, Rofiah A, Latinah M, Thahirahtul AZ, Zaridah MS, et al. Disease and risk factor perception among patients with coronary artery disease in Kuala Terengganu. Med J Malaysia. 1994 Sep;49(3):205-8.

[12] Jafary FH, Aslam F, Mahmud H, Waheed A, Shakir M, et al. Cardiovascular health knowledge and behavior in patient attendants at four tertiary care hospitals in Pakistan - a cause for concern. BMC Public Health. 2005;5:124. 1-16

[13] Khan MS, Jafary FH, Jafar TH, Faruqui AM, Rasool SI, Hatcher J, et al. Chaturvedi. Knowledge of modifiable risk factors of heart disease among patients with acute myocardial infarction in Karachi, Pakistan: a cross sectional study. BMC CardiovascDisord. 2006; 6: 18.

[14] Vartiainen E, Puska P, Jousilahti P, Korhonen HJ, Tuomilehto J, Nissinen A. Twenty-year trends in coronary risk factors in north Karelia and in other areas of Finland. Int J Epidemiol. 1994 Jun;23(3):495-504.

[15] Castelein P, Derr JR. Statisfcction and cardiac lifestyle. J Advnars 1995; 21:498-505 